\title{
Rediscovering The Roses of Eyam: A forgotten television play
}

Ben Lamb, Teesside University

\begin{abstract}
In 1973 playwright and television dramatist Don Taylor rewrote and directed his play The Roses of Eyam for UK television. The original play, which was staged at the Northcott Theatre in Exeter in 1970, has been somewhat disregarded in Theatre Studies criticism despite its worldwide popularity in educational circles. Similarly, the subsequent television play has been relatively overlooked in historical studies of British television despite the fact it was one of the most ambitious dramas of its time. This article examines Don Taylor's 1973 televisual adaptation in relation to his original production through archival research of production documents, interviews with producer David Rose, and a number of textual analyses. Analysing the process of adaptation the play had to undergo to fit with the conventions of 1970s studio productions will reassess established truisms present within adaptation scholarship regarding the visual language of studio-based television drama.
\end{abstract}

\section{Keywords}

$\underline{\text { Adaptation Studies }}$

Theatre Adaptation

$\underline{\text { Theatre Studies }}$

Television Adaptation 


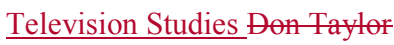

The play is a dramatization of extraordinary real-life events where the villagers of Eyam voluntarily quarantined themselves from August 1665 until October 1666 to prevent the bubonic plague contaminating the rest of Derbyshire. Although this isolation successfully prevented the plague spreading beyond their settlement, Eyam saw its population decline from 316 residents to 63 people. A total of 253 villagers had fallen victim to the terminal disease in fourteen months. Therefore, the educational qualities that come with this tale of "courage in the lifestyle of the seventeenth century', ${ }^{2}$ as television producer David Rose describes it, has seen The Roses of Eyam become canonized within the UK schooling system and reach schools as far afield as Australia. ${ }^{3}$ Its stark depiction of perseverance in the face of adversity continues to possess an enduring quality that resonates with each generation of school pupils.

Whilst The Roses of Eyam has gained its cultural status as a landmark play within the UK education system, its initial production eluded widespread recognition. Its 'world premier' took place on 23 September 1970 at the Northcott theatre in Exeter and featured then unknown actors John Nettles, David Suchet, Robert Lindsay and John Rhys-Davies. Despite a positive critical reception from The Stage and Screen Today, which claimed 'this is a play which ought to be heard of and seen many miles afield of Devon and Derbyshire' (Culverhouse 1970: n.p.), The Roses of Eyam was last staged on Saturday 10 October 1970 after just one run. Had it 
not been 'later successfully televised' (Speakman 2012: x) by BBC2 on 12 June 1973 it would have never received a national audience. Despite the ratings success of this televised reimagining of the play, which led to a repeat, The Roses of Eyam continues to be studied throughout schools in its original form. Little public knowledge of the televised version exists as it has never been broadcast since 1974, nor has it been commercially released.

This article will analyse the differences between the original play text and the television version, through the aid of archival research, to determine the process the theatre script had to endure to assimilate with conventions of studio-shot television drama in the 1970s. Such an analysis will challenge truisms that continue to endure throughout adaptation studies, particularly those expressed by André Bazin (2004), Sarah Cardwell $(2002,2012)$ and Val Taylor (1998).

Methodologically this analysis adopts a traditional comparative approach which compares the original source text with the television version as two separate textual entities to unearth observations about the adaptation process. Such an approach has been criticized for treating the meanings expressed in both the source material and adaptation as being trans-historical. This dehistoricization can fail to consider the development of adaptations as part of a meta-text that both the original text and its adaptations belong to. A comparative approach is used here because it represents the most effective method of analysis for this adaptation in particular. Viewers who watched The Roses of Eyam on $\mathrm{BBC} 2$ would have had no prior knowledge of the play nor would they have understood it as an adaptation. As the play was adapted for television three years after its initial theatre release, by the same author, there is not much of a historical gap to consider. Correspondingly as this broadcast represents the only existing adaptation there is little meta-text to 
investigate. Crucially, what this comparative analysis does is consider issues surrounding The Roses of Eyam's social and institutional contexts, intertextual practice and genre. Something which Brian McFarlane (1996), the forefather of comparative adaptation studies, is accused of neglecting in his analysis of the specific conventions that constitute different mediums and their narrative processes.

\section{Textual analysis}

Cardwell's study of classic-novel adaptations as a television genre offers a useful framework for this textual analysis. Although her work examines the transition that novels undergo when being translated into television, this article seeks to challenge her claims about the visual aesthetics of 1970 s studio-shot dramas as they continue to be understood in adaptation studies. Cardwell's belief is that the critical and commercial success of costume dramas including Brideshead Revisited (1981) and Pride and Prejudice (1995) was largely due to their rejecting of mainstream television drama conventions. Utilizing film cameras on location as opposed to using video cameras in the studio, the most common mode of television drama production in this period, ensured these dramas were perceived as being more 'serious, reflective, intelligent and thoughtful' (Cardwell 2002: 34). Cardwell makes these observations in relation to studio-shot adaptations of the 1970s stating that comparatively studio-based adaptations of plays and literature using video cameras were "conventionally "wordy" thus relying upon "verbal communication to convey not just story but also theme, mood and pace' (2012: 171). Using Persuasion (1971) as a metonym for all studio-based adaptations Cardwell explains that its visual style 'is subdued in terms of camerawork, and lacking in stylistic flair' (2012: 171). 
Through The Roses of Eyam this article will uncover how adaptations using video camera technology could distance themselves from other 'run-of-the-mill' broadcasts whilst being able to articulate theme, mood and pace in visual terms (Cardwell 2002: 98).

As a television adaptation, The Roses of Eyam is incredibly faithful to its original stage material and represents what Wagner (1975) classifies as a 'transposition'. The published theatre script, complete with stage directions, largely reads as if it is a word for word script of the television play itself. The omission of seemingly inconsequential dialogue, the inclusion of small additional scenes and slight changes to the way certain moments are staged initially appear to be insignificant. However, a detailed examination of the changes Taylor implemented amidst the material's transition from stage to television reveals the process of adaptation within studio productions of the 1970s was not as simplistic as has been characterized by adaptation scholarship. Video camerawork is not necessarily stagnant, invisible or non-existent.

Taylor's use of the close-up within this play achieves a distinctive intimacy that resonated with the public who praised the make-up of the plague victims for being 'remarkable', and 'horribly convincing' (BBC WAC M24/12/1). The plague is first revealed to have entered the village in both versions of the play following a joyous fete in Act One where all the villagers gather to celebrate the recent harvest. In the original play we learn that Eyam has been contaminated with plague when the residents congregate the morning after the fete to attend a clothes sale hosted by the village tailor George Vicars. Talking amongst themselves the villagers reveal to the audience that the clothing sale has been cancelled due to the tailor having fallen seriously and instantaneously ill. 
However, in the television version we are informed of Vicars' illness through the inclusion of an additional scene. As the fete draws to a close the camera cuts to a close-up of Vicars (Robin Parkinson) in his bed. Lying on his back with his right cheek resting on his pillow, we can see a collection of small boils on Vicars' left cheek. He is visibly unwell as he has a bright red complexion. He is sweating uncontrollably, breathing deeply and shaking. As the camera slowly zooms out, a large burst bubo seeping with green puss on the left side of Vicars' neck enters the frame. Then as he bolts upright to vomit blood into a wooden bowl a large inflamed bubo on his right cheek becomes visible which has swelled his face beyond recognition. This is a very stark transition from a brightly lit fayre that is framed through a wide angle shot and accompanied by joyous sounds to a darkly lit and confined setting. Swiftly undercutting the previous jubilation the only sound that can now be heard is Vicars' grunting to signify the excruciating pain he is experiencing. Following this scene the television play then resumes to the original theatre script as the villagers gather outside and explain what they have heard about Vicars' illness.

Here an audience has been provided access to the extent of Vicars' suffering as each ailment is revealed in a chillingly intimate manner that would not have been possible in the theatre. This scene adds a feeling of horror that is not present in the original play. Thus an additional mood has been created in visual terms through the camerawork and make-up that received such high praise from viewers.

This combined use of close-ups and make-up is used to a similar end later on in the television play to frame a montage of dead-bodies midway through Act Three. In the original play Marshall Howe talks to Bedlam listing the dates and times that residents have recently died. Howe describes who they were whilst they are revealed on another part of the stage. In the television version, though, this dialogue is 
displaced to the non-diegetic narrator. Within one scene a camera provides a close-up of Edward Thornley (Mike Pratt) who lies dead in a cart in the centre of the village, his face riddled with bust buboes on his cheek, forehead, shoulder and mouth. Then the camera immediately cuts to Elizabeth Swanne's (Maureen Morris) body which lies in her bedroom with blood running from her mouth. Following this shot Lydia Chapman's (Malya Woolf) body is revealed, sat up against the exterior of a wall near the centre of the village. Chapman is decidedly pale as if sunken into the surroundings. Combined, these three relatively swift cuts are able to transcend the space of the studio set to display this information. Not only does this montage again provide a degree of harrowing intimacy to this tragic scene but it does so at a significantly faster pace than would have been achievable within the confines of the original theatre production.

Cardwell's view is that a rejection of 'relatively fast editing, a reliance on close-ups, and the use of video (as opposed to film)' granted classic 1980s serials their superior status in relation to other television dramas. Here however, the use of these three conventions made The Roses of Eyam standout from other broadcasts of the 1970s. A total of 90 per cent of the BBC Viewing Panel thought The Roses of Eyam was 'grimly realistic' (BBC WAC M24/12/1) and many viewers acclaimed it as one of the most impressive and compelling television broadcasts they had ever seen. Sets, costumes and production as a whole were generally commended and said to be 'realistic' (BBC WAC M24/12/1). A vast number of letters can also be found in the $\mathrm{BBC}$ Archives which were sent from people belonging to a range of classes, professions, ages and geographical locations praising Taylor and Rose for their production and asking where to obtain a copy. These include a librarian from South Devon who has had ample requests for a published edition of the script; the 
headmistress of a girls school in Barnsbury who would like to study the play and television version in class; a producer at the Barbican Theatre Club who would like to produce the play for the amateur stage; and the Editorial Assistant of the History of Medicine publication in London who asks if a copy can be used 'for inclusion in a future issue of our journal' (BBC WAC M24/12/1). Here Taylor's use of familiar studio-based conventions, executed in a particularly intensive manner, are actually what differentiated The Roses of Eyam from other dramas broadcast at the time.

Cardwell's logic in her criticisms of 1970s adaptations is that their reliance on the spoken word is synonymous with their apparent lack of visual expressivity. She claims that in relation to the 1980 s these 1970 s adaptations exhibit an 'over literariness through an excessive reliance upon language and a downplaying of the pictorial or visually impressive or expressive' (2002: 82). However, the relationship between expressive camerawork and the spoken word is not always dichotomous within studio-based drama. Don Taylor was a dramatist who worked in both the theatre and television industries and 'had a passion for dramatic poetry' as well as 'writers who used language imaginatively' (1990: 17). He respected the spoken word and clearly valued a traditional use of language over directors who preferred using film cameras who he deemed to be 'grainy realists who imitated the incoherence of speech' (Taylor 1990: 17). Yet at the same time Taylor believed:

The cameras were the story, they were the expressive instrument, as words were for the poet $[\ldots]$ So I knew that my cameras would not stand back and observe a play being acted. They would get in among the sweat and the anger 
and the fear. They would go close to the actors, inhabit their dilemmas, swirl and swing inside the action of the play, not on its periphery. (1990: 22)

This idea of using the camera to 'swirl and swing inside of the action' (Taylor 1990: 22) is pertinently demonstrated through Taylor's use of tracking shots to frame crowd scenes throughout the play. In the original theatre production seeing all the villagers gathered together as their numbers decline works as a key theme at several moments in the production. The stage instructions denote that the 'main purpose' of these gatherings is to observe the number of villagers 'diminish, thus creating the visual image of the whole play' (Taylor 2012: 9). In the television version, rather than the camera simply observing the dwindling number of villagers, its movements further emphasize this theme. During the fete scene in Act One a camera mounted on a crane briskly moves through the crowds swooping, panning and tracking in all directions in accompaniment to the joyous diegetic music to reflect Eyam's collective merriment.

Then in Act Two the villagers headed by Edward Thornley confront William Torre (Walter Sparrow), whose son has recently died. They forcibly order Torre to stay in his house to prevent the plague from spreading further. The camera tracks across the lined rows of people from left to right observing their scowling expressions. All the characters are completely motionless standing as if statues. The residents are now becoming trapped and confined by their community. Rather than feeling a sense of freedom, merriment, or togetherness they have begun to entrap one another. The camera tracks at a much slower speed and moves steadily in 
comparison to the freewheeling motions it utilized in the fete scene to reflect how the villagers' movements have now become considerably restricted.

The last crowd scene occurs in Act Three when the remaining villagers congregate on the grassy Delph for a sermon delivered by Mompesson (Ronald Pickup). In this 30 second-long shot, one of the longest in the play, the camera tracks at an even slower pace than in the previous crowd scene. The actors stand with their sides to the camera as it creeps past each villager drawing attention to the gaps in between each individual as many have died at this point. Each person has a sullen expression and they are all seemingly despondent to their surroundings. Their situation has again deteriorated to the point where they have lost all hope and are awaiting their inevitable deaths. In the original play the audience observes all the villagers enter the stage for each crowd scene but in the television version the actors are already placed in position relying on the camera help to articulate their collective mindset. For each gathering the camera's movements become slower and its shot duration lengthens to replicate the people's worsening situation and their increasingly tortuous existence.

Through these crowd scenes Taylor's tracking shots emphasize the recurring theme of diminishing villagers. The camera's repeated change in speed, duration and movement draws attention to the declining number of villagers whilst embodying the survivors' weakening demeanour. Often academic writing that champions studioshot television drama concentrates on how characters are costumed, where they are positioned in relation to the set design, and how they interact with props. Helen Wheatley's (2005) textual analysis of Lady Marjorie in Upstairs Downstairs (1971$\underline{75)}$, is seminal to television studies in this respect because it proves just how expressive and visually sophisticated the television studio space can be in costume 
dramas. However, the camera also has an expressive role to play in studio productions that has not been granted as much critical significance. The video camera in the studio can embody a role that is not neutral or 'emasculated' as Kennedy Martin has claimed (19651964: 25). The televisual treatment of the theatre play relies on camera movement to convey the increased hopelessness of the villager's predicament rather than having actors explain this theme of loss through their immediate dialogue as believed to be a principal convention of 1970s studioshot adaptations by Cardwell.

The visual expressivity of the video camera at these specific moments in The Roses of Eyam can help to disprove Cardwell's view that 1970s studio-shot adaptations overly rely on the spoken word. However, this visual expressivity could also be seen to simultaneously substantiate another accepted truism within adaptation studies. Usually the theatre is believed to provide a viewer with a higher degree of autonomy compared to its on-screen adaptation. André Bazin claims that the theatre is a medium which "calls for an active individual consciousness whilst the psychology of the cinematographic image offers a natural incline leading towards a sociology of the hero characterised by a passive identification' (2004: 99). This view is reiterated by Val Taylor's examination of the BBC's 1991-studio-shot adaptation of Caryl Churchill's Top Girls_(1991). She argues that studio-shot television adaptations are identical to the cinema as their purpose is also to draw a spectator into 'empathic identification' (1998: 138) with a lead character. Without the ability to look at any part of the set independently from the camera's gaze, as happens in the theatre, an audience loses 'their own agency within the total process' (Taylor 1998: 139). 
Subscribing to Bazin's view Taylor's analysis of Top Girls is one of only few studies to theoretically analyse the adaptation process plays endure when being transferred from the theatre to a studio-shot television production. Correspondingly Don Taylor's use of expressive camerawork in The Roses of Eyam crowd scenes can prove Val Taylor's view that an audience loses a degree of agency. Here a spectator can no longer observe the characters' entrances to the set independently from the gaze of a camera. However, as a result of the adaptation process, the television version is actually less invested in Mompesson's individual struggle compared to the original play. This complicates the notion that the purpose of all studio-shot television using video cameras is to draw a spectator into an 'empathetic identification' with a principal protagonist (Taylor 1998: 138). The collective plight of the villagers becomes central to the television version. Through these uses of close-ups and tracking shots we are repeatedly made to observe the villagers' suffering rather than align with a particular protagonist's actions. This is particularly evident in the delph speech of Act Three where a focus on the despondent villagers is prioritized over the delivery of Mompesson's sermon.

Furthermore a number of soliloquies are omitted which creates a version of the play that contains less introspection of its principal character. In the original play Mompesson frequently expresses self-doubt through soliloquys having convinced the villagers to quarantine themselves. These soliloquys are dropped from the television version. The most significant omission is the original play's most iconic and unsettling scene. After Mompesson and his wife Catherine have evacuated their young children, which defies their advice to the villagers, Catherine starts to display symptoms of the plague. Immediately after Mompesson discovers these symptoms all the stage lights fade around him as he kneels 'in a pool of light, with only the 
cyclorama lit behind him' (Taylor 2012: 119). The stage instructions state his 'meeting is not a naturalistic one that can be defined in terms of time and place. It is a meeting of their private terrors and thoughts not their physical bodies' (Taylor 2012: 119). As Mompesson kneels five characters that have died enter the stage to list dates and the names of others who fell victim to the disease. The five darkly shrouded figures then stand over Mompesson pointing at him accusingly.

Although the television play utilizes a visual discourse that can transcend different spaces, as featured in Act Three's montage of dead bodies, it does not transcend the linear unveiling of time and space. This could be considered as evidence of an audience's diminished autonomy because they are prevented from interpreting abstract scenes that depict a different mode of reality. However, the cutting of these scenes actually decentre Mompesson as the all-encompassing protagonist of the piece and instead focuses on the village as a collective. Therefore this distinction that the theatre provides an audience the ability to autonomously interpret the actions of characters compared to studio-shot television fiction, which is supposedly more interested in the empathetically aligning its viewers with a principal protagonist, is not necessarily as clear-cut as it is characterized in adaptation scholarship.

This focus on the village community at the expense of a protagonist's existential struggle is furthered by the changes made to the play's ending. The concluding scene of the original text is particularly bleak. In the last line of dialogue Marshall Howe tells Bedlam 'let's be quiet now, boy. We'll stand here, watching the lamps go out, till it's all quiet, and peaceful, and dark' (Taylor 2012: 137). Then "music comes to a slow climax and we see the two figures, the giant and the cripple, silhouetted against the empty wastes of the stage the lights fade as the curtain slowly 
falls' (Taylor 2012: 137). Comparatively the television version concludes by informing its audience 'the play may be fiction but the story is true, there are gravestones to prove it'. A film camera then displays one of the gravestones of the plague victims that can still be found in Eyam as the credits roll on-screen. The ideological message has changed from stressing the inherent insignificance of human existence when pitted against greater uncontrollable forces to arguing that the quarantine was worth enduring for the future preservation of the village.

\section{Production context}

A significant reason behind this renewed focus on the villagers partly emanated from the BBC's English Regions Drama department. A prerequisite of playwrights who worked for this department was that they had to 'either live in or [...] have particular concern for the regions' (Anon. 1972: 73). When writing the initial play Taylor had had no contact with the real village. This changed under BBC English Regions Drama where he researched the history closely with residents. There was a danger that concluding the play with its originally bleak and disquieting conclusion could have disheartened this close relationship English Regions Drama had been keen to maintain. Thus the use of a film camera at the end of the television play to capture the village as it existed in 1973 invites a viewer to admire the history, legacy and heritage of the real village. Evidently these changes worked in maintaining a close relationship with the community as David Rose was asked to open Eyam's Autumn Fair on 1 December 1973. Similarly locals personally congratulated Rose and Taylor for their play. Notably a woman from Derbyshire sent a letter to English Regions 
Drama praising them for providing 'the right feel of the Derbyshire villages I know and love' (BBC WAC M24/12/1).

Whilst this article disagrees with Cardwell's view of 1970s studio-based adaptations her theoretical analysis of 1980s and 1990s classic-novel adaptations does provide a useful schema that can be applied to 1970s adaptations. Cardwell's logic is that adaptations construct their meanings through the 'televisual synthesis of represented past and contextual present' (2002: 97). The way classic-novel adaptations of the 1980s and 1990s negotiated this balance was by utilizing film camera technology to present themselves as a 'refuge' from 'run-of-the-mill' television (Cardwell 2002: 98). At first glance The Roses of Eyam adaptation does not appear to differentiate itself from other everyday drama as it was shot in the studio in line with mainstream practice of the time. Nevertheless an intertextual analysis of its production context and marketing strategy proves that adaptations characterizing themselves as a higher class of production was a practice that predates classic-novel adaptations of the 1980s and could be achieved by studio-based drama in the 1970s through different intertextual methods.

The television adaptation of The Roses of Eyam came into being as a result of the BBC's regional reorganization. On 10 November 1971 a seven million pound Pebble Mill studio complex in Birmingham was officially opened. As part of these studios producer David Rose was appointed Head of the new English Regions Drama department. Alongside script editor Barry Hanson Rose had a brief to produce original and contemporary regional television drama for the network. Rose made it his personal mission to utilize film cameras on real locations as film technology was becoming cheaper to use and more readily available. As opposed to shooting drama in a studio with video cameras the majority of the full-length plays produced by 
English Regions Drama for national television were filmed on location. Although a number of half-hour plays, series and serials produced by English Regions Drama were shot in Pebble Mill Studios, it was these filmed full-length plays that provided English Regions Drama with its reputation. As David Rose explained:

Because of where we were and my desire to reflect regional life, the landscape and the community, we tried to make as many of those [...] Play for Todays on film as possible, to somehow get a feeling of the outlook of the regions. (Millington and Nelson 1986: 25-26)

With this context in mind The Roses of Eyam stands out when placed alongside the other full-length plays produced by English Regions Drama under David Rose. It was not written especially for television, it was not shot on film, nor was it set in contemporary Britain. Additionally what made The Roses of Eyam particularly unique was its scale of production. Stretching far beyond the traditional style of studio drama at that time, the two-hour long play, containing 42 different characters and thirteen different sets, took five months preparation, and was rehearsed for four weeks in London before an intensive four day shoot at Pebble Mill from 3 to 6 April 1973. Therefore, The Roses of Eyam's unique position as an ambitious studio-shot English Regions Drama production, surrounded by other fulllength filmed dramas, is what made it stand out in television the schedule. Philip Purser of The Sunday Telegraph in particular saw the The Roses of Eyam as a 'disappointment' because it came from 'the BBC's English Regions group under David Rose which has rightly prided itself on a strong sense of place, on being 
rooted in reality rather than fiction' (1973: n.p.). Furthermore David Rose himself has said

In a way, I surprised myself by producing Don Taylor's play [...] It was Don Taylor's proposition that I must have been compelled by. I frankly felt that his approach was too close to theatre - even somewhat 'old fashioned'. But I backed it. ${ }^{4}$

The very commissioning of this two-hour long drama as a studio play, within the context of English Regions Drama, is what differentiated it from other fictional drama both by its production team and the national press.

In addition to this production context Rose and Taylor deliberately headed a marketing campaign that intertextually depicted the broadcast as something different from regular drama. As part of this campaign Taylor hosted two back-to-back screenings of his play in the parish church of St Lawrence located in the centre of Eyam. The church held a total of 250 people and both screenings sold out. The Yorkshire Post's Ian Gretton commended how a total of eight 26 inch television sets which screened 'the most ambitious production ever mounted [...] held the complete attention of the audience' as the play was 'watched in respectful silence' (1973: n.p.). Similarly The Guardian claimed 'men, women, even very small children sat on the narrow wooden pews for more than two hours with an intent stillness' (Fiddick 1973: n.p.). The Guardian was in awe of the experience the national audience was unable to partake in; 'There was an element of shared experience in, their two communal 
showings that will never exist for those of us who sit in our own homes tomorrow night' (Fiddick 1973: n.p.).

This screening was used to garner interest in the play before its broadcast. It seemingly worked as the press depicted the screening, and subsequently the text itself, as something that was unique and that had never been attempted before. This was furthered by a documentary broadcast the night before the television play called This Story is True (1973). As Rose has said, it 'proved to be an excellent and effective trailer for the play'. The historical documentary was shot on film cameras within the real Eyam to interview historians and residents about this particular chapter of history. As such this trailer added a degree of historical gravitas to the televised play whilst signalling its broadcast as something special that was essential viewing the following evening.

\section{Conclusion}

This article has redressed the lack of critical attention The Roses of Eyam has received. Through a textual analysis it has challenged how the visual composition of 1970s studio productions continues to be understood within adaptation scholarship. Whilst writer and director Don Taylor was an advocate of drama that focused on dialogue, traditional language and the spoken word, his direction still utilizes an expressive mode of camerawork. His use of close-ups create a chillingly intimate atmosphere not achievable in the theatre. His editing adds a degree of pace and his tracking camera movements convey the recurring theme of loss whilst reflecting the village community's collective thought processes. Such camerawork challenges Cardwell's view that only dialogue could articulate 'theme, mood and pace' (2012: 
171) in the studio setting. Camerawork represents integral part of the television studio's visual discourse and thus warrants further critical attention.

However, compromises had to be made in order for Taylor's adaptation to honour English Regions Drama's relationship to its regions. This production context helped to create a drama that is less interested in an individual's crisis and is more concerned with the preservation of community. Whilst theatre plays continue to be understood within adaptation studies as a medium that grants audiences a higher degree of agency, studio-shot television is not necessarily as interested in psychologically aligning itself with a protagonist like the cinema. Further investigation is required to discern the differences that exist between all three mediums

Furthermore events and texts produced in addition to the television play have revealed that characterizing televised adaptations as texts separate from mainstream drama is a practice that predates Brideshead Revisited. Rather than trying to dissociate itself from regular television drama on an immediate textual level, English Regions Drama saw The Roses of Eyam as a different type of drama compared to its usually filmed full-length plays and so went to great lengths to publicize the drama as something unique.

Ultimately The Roses of Eyam continues to endure throughout the UK schooling system. It is not considered a landmark text in Theatre Studies nor does it hold a place in the canon of great British dramas within Television Studies. Nevertheless it is a significant television play that can be used to challenge relatively clear-cut understandings of studio-based television drama's visual discourse, television's relationship to the theatre and television adaptations as a genre. Perhaps 
a commercial release would warrant its study in schools alongside the original play text.

\section{Acknowledgements}

My thanks to Erin Walcott and all the staff at the Northcott Theatre Archive, University of Exeter; Jeff Walden at the BBC Written Archives, Caversham; Vanessa Jackson, Birmingham City University; John Wyver, University of Westminster; Jonathan Bignell, University of Reading and Stephen Lacey, University of South Wales, and David Rose himself for taking the time to be interviewed. This article is one of the outcomes of the research project 'Spaces of Television: Production, Site, and Style', funded by the Arts \& Humanities Research Council from 2010 to 2015. The project was led by Jonathan Bignell, Head of the School of Arts and Communication Design at the University of Reading.

\section{References}

Bazin, André (2004), What is Cinema?: Volume 2, California: University of California Press.

\section{Brideshead Revisited (1981, UK: ITV/Granada)}

Cardwell, Sarah (2002), Adaptation Revisited: Television and the Classic Novel, Manchester: Manchester University Press. 
(2012), 'Literature on the small screen', in Timothy Corrigan (ed.), Film and Literature: An Introduction and Reader, London: Routledge, pp. 168-78.

Cooke, Lez (2003), British Television Drama: A History, London: BFI.

(2012), A Sense of Place: Regional British Television Drama, 1956-82,

Manchester: Manchester University Press.

Corrigan, Timothy (ed.) (2012), Film and Literature: An Introduction and Reader, London: Routledge.

Culverhouse, Jonathan (1970), 'Villagers' terrible choice in Plague is basis of new play', The Stage and Television Today, Northcott Theatre Archive, University of Exeter, Exeter, 1 October.

Fiddick, Peter (1973), 'Peter Fiddick reports on an ironical TV event', The Guardian, 11 June, BBC WAC M24/12/1.

Gretton, Ian (1973), 'Village history on TV fills Church twice', Yorkshire Post, 11 June, BBC WAC M24/12/1.

Jacobs, Jason (2000), The Intimate Screen: Early British Television Drama, Oxford and New York: Oxford University Press and Clarendon Press. 
Johnson, Catherine and Turnock, Rob (eds), ITV Cultures: Independent Television over Fifty Years, Maidenhead: Open University.

Kennedy Martin, Troy (19645), 'Nats go home: First statement of a new drama for television', Encore, 48, pp. 21-33.

McFarlane, Brian (1996), Novel to Film: An Introduction to the Theory of Adaptation, Oxford: Clarendon Press.

Millington, Bob and Nelson, Robin (1986), Boys from the Blackstuff: The Making of TV Drama, London: Comedia.

\section{Persuasion (1971, UK: ITV/Granada)}

Pride and Prejudice (1995, UK: BBC1)

Purser, Philip (1973), 'The Plague's the thing', Sunday Telegraph, 11 June, BBC WAC M24/12/1.

Ridgman, Jeremy (ed.) (1998), Boxed Sets: Television Representations of Theatre, Luton: University of Luton Press.

The Roses of Eyam (1973, UK: BBC2) 
Speakman, Ray (2012), 'Introduction', in R. Speakman (ed), The Roses of Eyam, Harlow: Heinemann, pp. vii-X.

Taylor, Don (1990), Days of Vision Working with David Mercer Television Drama Then and Now, London: Methuen.

(2012), The Roses of Eyam, Harlow: Heinemann.

Taylor, Val (1998), 'Altered images: Theaterical and filmic space in Top Girls', in Jeremy Ridgman (ed.), Boxed Sets: Television Representations of Theatre, Luton: University of Luton Press, pp. 129-39.

This Story is True (11 June 1973, UK: BBC2)

(11 June 1973, BBC2).

Top Girls (1991, UK: BBC2)

Wagner, Geoffrey (1975), The Novel and the Cinema, New Jersey: Fairleigh Dickinson University Press.

Wheatley, Helen (2005), 'Rooms within rooms: Upstairs downstairs \& the studio costume drama of the 1970s', in Catherine Johnson and Rob Turnock (eds), ITV Cultures: Independent Television over Fifty Years, Maidenhead: Open University, pp. $143-58$. 


\section{Contributor details}

Dr Ben Lamb is Research Lecturer in Media Studies at Teesside University. As a television historian, his established research examines representations of social class, gender and political discourse across genres of factual and fictional programming. $\mathrm{He}$ is also interested in the relationship between aesthetics and ideology, and how different television production systems have impacted upon the resultant modes of realism. Ben's current research project examines how past regional television disseminated the purpose and role of the welfare state throughout the 1960s, 1970s, and $1980 \mathrm{~s}$

\section{Contact: Dr Ben Lamb}

$\underline{\text { School of Arts and Media }}$

Teesside University

Borough Road

Middlesbrough

TS1 3BA

E-mail:b.lamb@tees.ac.uk

Notes

\footnotetext{
${ }^{1}$ See AQA's http://filestore.aqa.org.uk/subjects/AQA-4240-W-TRB-RL.PDF and OCR's http://ocr.org.uk/Images/74399-unit-a581-page-to-stage-specimen.pdf as particular examples.

${ }^{2}$ Interview with the author.
} 
${ }^{3}$ Upon uploading my interview with David Rose

http://www.pebblemill.org/blog/roses-of-eyam-ben-lamb/ to academia.edu, four Australian children found it through google by searching 'Roses of Eyam essay guide', 'Roses of Eyam essay questions' and 'Roses of Eyam essay tips'.

${ }^{4}$ Interview with the author. 